\title{
A MEDIAÇÃO LITERÁRIA NA LEITURA E NA CONSTRUÇÃO DE POEMAS-OBJETO ${ }^{1}$
}

\section{LITERARY MEDIATION IN READING AND CONSTRUCTION OF POEM-OBJECT}

\section{LA MEDIACIÓN LITERARIA EN LA LECTURA Y EN LA CONSTRUCCIÓN DE POEMAS-OBJETO}

\author{
NEITZEL, Adair de Aguiar \\ neitzel@univali.br \\ UNIVALI - Universidade do Vale do Itajaí \\ MORAES, Taiza Mara Rauen \\ taiza.mara@univille.br \\ UNIVILLE - Universidade da Região de Joinville \\ SANTOS, Amanda Demétrio dos \\ amandademetriods@gmail.com \\ UNIVALI - Universidade do Vale do Itajaí
}

\begin{abstract}
RESUMO Este artigo discute as possibilidades de mediação literária do poemaobjeto explorada pelos bolsistas do PIBID de Letras da Universidade do Vale do Itajaí em uma escola da Rede Municipal de Itajaí, Santa Catarina. Centra-se a atenção no poema-objeto por possibilitar a compreensão da literatura como arte. A metodologia utilizada é qualitativa e de intervenção, e os instrumentos de coleta de dados foram portfólios produzidos pelos bolsistas. As análises foram feitas por meio da análise de conteúdo. O aporte teórico foi Neitzel e Carvalho (2016), Barthes (2003), Heidegger (2003) e Larrosa (2016). As propostas literárias possibilitaram aos bolsistas uma revisão de postura, a de "mestres emancipadores", e a sala de aula passou a ser espaço de fazer experiência, onde os estudantes foram protagonistas de sua própria aprendizagem.
\end{abstract}

Palavras-chave: Formação de leitores. Mediação literária. Poema-objeto.

ABSTRACT This paper discusses the possibilities of literary mediation of the poemobject explored by the scholarship holders of the Teaching Initiation Scholarship Institutional Program (PIBID) of the Portuguese language and literature course from the Universidade do Vale do Itajaí at a school of the Municipal Network of Itajaí, Santa Catarina, Brazil. Attention is focused on the poem-object since it enables the understanding of literature as art. The methodology used is qualitative and interventional, and the instruments of data collection were portfolios produced by the students. Analyzes were carried out through content analysis. The theoretical contribution was Neitzel and Carvalho (2016), Barthes (2003), Heidegger (2003) and Larrosa (2016). The literary proposals allowed the scholarship holders a revision of

\footnotetext{
${ }_{1}^{1}$ Pesquisa financiada pela CAPES (PIBID) e CNPQ (Edital Universal/2016).
} 
posture, the one of "emancipating masters", and the classroom became a place of experience, where students were protagonists of their own learning.

Keywords: Education of readers. Literary mediation. Poem-object.

RESUMEN Este artículo discute las posibilidades de mediación literaria del poemaobjeto explorada por los becarios del PIBID de Letras de la Universidade do Vale do Itajaí en una escuela de la Red Municipal de Itajaí, Santa Catarina. Se centra la atención en el poema-objeto por posibilitar la comprensión de la literatura como arte. La metodología utilizada es cualitativa y de intervención, y los instrumentos de recolección de datos fueron portafolios producidos por los becarios. Los análisis se realizaron a través del análisis de contenido. El aporte teórico fue Neitzel y Carvalho (2016), Barthes (2003), Heidegger (2003) y Larrosa (2016). Las propuestas literarias posibilitar a los becarios una revisión de postura, la de "maestros emancipadores", y el aula pasó a ser espacio de hacer experiencia, donde los estudiantes fueron protagonistas de su propio aprendizaje.

Palabras clave: Formación de lectores. Mediación literaria. Poem a objetos.

\section{INTRODUÇÃO}

Palavras são seda, aço.

Cinza onde faço poemas, me refaço. Lindolf Bell (O Código das Águas).

Lindolf Bell (2001) aciona a poética como um convite ao leitor para pensar na palavra e na experiência sinestésica de reconstrução de mundos pela palavra. $O$ poeta identifica as palavras como seda e aço e, com esse oximoro, cria pistas para compreender como a linguagem pode nos provocar e transformar: cinza onde faço poemas, me refaço. A palavra poética vela e desvela a polivalência de sentidos, fragmentos da imaginação ou de experiências vividas pelo autor e do contexto histórico que a situam em um tempo e espaço histórico, linguagem que convida o leitor crítico ao gesto de interpretação criativa que busque operar uma sondagem que capte a polivalência de sentido da linguagem da arte. Esse processo de construção de sentidos depende da nossa relação com a linguagem e das possibilidades que nos permitimos de fazer uma experiência com ela. "Fazer tem aqui o sentido de atravessar, sofrer, receber o que nos vem ao encontro", conforme afirma Heidegger (2003, p. 121).

Tendo em vista esse conceito de Heidegger (2003), traremos, ao longo deste artigo, considerações sobre a personagem Rosálio, da obra O Voo da Guará 


\section{Atos de Pesquisa em Educação - ISSN 1809-0354 \\ Blumenau, v.14, n.1, p.101-122, jan./abr. 2019 \\ DOI: http://dx.doi.org/10.7867/1809-0354.2019v14n1p101-122}

Vermelha, de Maria Valéria Rezende (2014) - como exemplar de experiência com o literário. Rosálio, habitante de uma comunidade rural, nos confins do Brasil, onde ninguém dominava a habilidade da leitura, é movido pelo desejo de aprender a ler, que se amplia a cada dia, sonho que é diluído por intermédio de Bugre, iniciado no universo dos livros, que, dele, recebe como herança uma biblioteca literária. Desse modo, trazemos à baila a palavra literária como propulsora de reflexões - um poema de Lindolf Bell (2001) e uma narrativa de Rezende (2014) - porque ambos os textos nos convidam a refletir sobre a relação que estabelecemos com a leitura do literário, tema desta pesquisa.

Nosso contato diário com a literatura impulsionou-nos a questionar como se forma o leitor do literário e como o mediador de leitura pode auxiliar a transformar a leitura em uma possibilidade de fazer uma experiência com a linguagem. Este é um dos desafios dos cursos de formação inicial de professores de Letras: explorar formas de introduzir o texto literário em sala de aula, possibilitando que a leitura seja um fazer experiência. Se Rosálio era um amante das histórias que ouvia, foi porque conviveu com elas, sentiu-as e, por elas, afetou-se. A literatura oral associada àquela caixa de livros deixada como herança pelo Bugre alimentou o seu desejo pela leitura.

Entendemos que, quando estamos no ensino formal, as atividades de leitura propostas aos alunos dependem da concepção do professor acerca da literatura. Se a compreendemos como arte, os textos selecionados serão lidos a partir de mediações e estratégias de leitura críticas que apreendam vários níveis de representação da palavra e que respeitem a função estética do texto literário. Tendo em vista que o Programa Institucional de Bolsas de Iniciação à Docência (PIBID) de Letras da Universidade do Vale do Itajaí (UNIVALI) - Santa Catarina - tem como objetivo explorar mediações do literário pelo viés da fruição, elegemos esse programa como lócus para desenvolvimento desta pesquisa. O PIBID é um programa de iniciação à docência que insere futuros professores em experiências inovadoras que agregam saberes docentes à sua formação profissional. Todas as atividades desenvolvidas pelo grupo de bolsistas na escola são supervisionadas por um professor da universidade e orientadas diretamente por um professor da rede de 


\section{Atos de Pesquisa em Educação - ISSN 1809-0354 \\ Blumenau, v.14, n.1, p.101-122, jan./abr. 2019 \\ DOI: http://dx.doi.org/10.7867/1809-0354.2019v14n1p101-122}

ensino, elaboradas de acordo com o planejamento semanal construído por meio de estudo e diálogo entre bolsistas, supervisor e coordenadora de área.

Dentre as diversas mediações do literário propostas pelos bolsistas do PIBID, selecionamos uma em que o grupo trabalhou com o poema-objeto. Dessa forma, este artigo tem como objetivo discutir as possibilidades de mediação literária do poema-objeto exploradas pelos bolsistas do PIBID de Letras da UNIVALI, no Centro de Educação em Tempo Integral Napoleão de Souza (CEDIN), localizado na cidade de Itajaí, Santa Catarina, na Rede Municipal de Ensino, cuja comunidade atende às crianças de vulnerabilidade social.

A concepção que norteia as atividades do PIBID de Letras é a da literatura fruitiva, que, segundo Barthes (2003), é proporcionada pela revelação que se estabelece entre o leitor e a obra, ou seja, pelo jogo que o texto encena, que convida - leitor a entrar nos seus interstícios. Ao pensar na literatura como arte, necessitamos introduzi-la em sala de aula para ser apreciada como objeto artístico e estético. Com foco na formação de leitores, o PIBID atua pelo viés da educação estética, uma vez que o aprendizado não se realiza apenas pela cognição, mas também por meio dos sentidos, pela experiência. Entendemos que a experiência com a linguagem literária compreendida como arte é bem distinta daquela da aquisição de conhecimentos sobre a linguagem. Como bem lembra Heidegger (2003, p. 122), "[...] uma coisa são os conhecimentos científicos e filosóficos sobre a linguagem e outra é a experiência que fazemos com a linguagem".

\section{METODOLOGIA}

Esta é uma pesquisa qualitativa e de intervenção, pois, na pesquisaintervenção, o pesquisar e o intervir são processos que ocorrem simultaneamente, indissociáveis. Ela foi desenvolvida no CEDIN, cujos sujeitos de pesquisa foram sete bolsistas do PIBID de Letras UNIVALI. Duas pesquisadoras são bolsistas do PIBID, uma atuou como coordenadora de área e a outra como bolsista de iniciação à docência e as três participam no desenvolvimento de um projeto de pesquisa sobre a mediação em leitura no âmbito do PIBID de Letras, aprovado pelo edital Universal/ 


\section{Atos de Pesquisa em Educação - ISSN 1809-0354 \\ Blumenau, v.14, n.1, p.101-122, jan./abr. 2019 \\ DOI: http://dx.doi.org/10.7867/1809-0354.2019v14n1p101-122}

Conselho Nacional de Desenvolvimento Científico e Tecnológico (CNPq). O PIBID de Letras atendeu a duas turmas, uma no horário matutino e outra no vespertino. $\mathrm{O}$ instrumento de coleta de dados foram os portfólios dos bolsistas, planejamentos e outros registros das ações disponíveis no ambiente virtual da instituição. Para análise, empregamos a análise de conteúdo. Selecionamos para este artigo apenas uma das atividades desenvolvidas com os alunos da Educação Básica que envolve o poema-objeto. Ela foi construída ao longo de cinco encontros, sendo um para planejamento, três na escola para implementação, e um para avaliação e socialização dos resultados.

\section{O POEMA-OBJETO: UM OBJETO CONCEITUAL}

O fazer uma experiência com a linguagem implica em romper com alguma coisa e, para Heidegger (2003), o rompimento dá-se onde algo falta, isto é, quando renunciamos a conceitos ou concepções que não nos permitem ampliar nossas percepções e sentidos. Diante do poema de Lindolf Bell (2001), questionamo-nos: Como as palavras podem ser seda e aço? Para entrar no jogo poético, precisamos despir-nos do sentido literal das palavras e enveredarmo-nos por suas fissuras. No entanto, renunciar, para Heidegger (2003), não significa perder, mas, sim, reanunciar, dando-se essa caminhada na relação com a palavra, a qual passa a ser alterada, transformada. Precisamos, assim, olhar para ela com outras lentes, aumentadas, renunciando à tentação de fazer dela tão somente um texto que permite ampliar nossa proficiência linguística. Lembremos que, para Heidegger (2003, p. 137), fazer a experiência com algo exige que "[...] isso nos alcance e comova, que nos venha ao encontro e nos tome, transformando-nos em sua direção".

Tendo em vista essa compreensão, os pibidianos escolheram mediar em sala de aula o poema-objeto que expressa a fusão da poesia e do design, é um objeto entre outros objetos, projetado para aproximar as coisas do poético. É, portanto, decorrente de uma percepção leitora de que o poema não é a representação de um fato estanque, não-transcendente em sua conexão com a cultura, pois a redução 
fenomenológica não se realiza em sua amplitude. Segundo Merleau-Ponty (1999), a única maneira de manter a intimidade com o mundo é retornando à percepção primeira da coisa, ou seja, quando o ser humano se depara com algo que se apresenta diante de sua consciência, em primeira instância. Ele percebe esse objeto em harmonia com a sua forma, a partir de sua consciência perceptiva. Após perceber o objeto, este entra em sua consciência transformando-se em um fenômeno.

O poema-objeto alinha-se aos princípios da poesia concreta (movimento literário que ganhou força na década de 1950, no Brasil), prioriza a forma e não o verso ao explorar a ideia de que a sintaxe espacial ou visual é centralizadora no processo comunicativo. Sua polissemia conceitual insere o leitor em uma experiência fruitiva e de reflexões para a construção de significados. Os estudantes/leitores em contato com esse objeto literário passam a rever seus conceitos sobre a literatura e compreendê-la como uma arte que transcende a folha plana para outros suportes tridimensionais (Imagem 1). Os bolsistas, ao se apropriarem do literário em suas múltiplas dimensões, assumem uma postura de mestres emancipadores, mediadores de encontros com a arte.

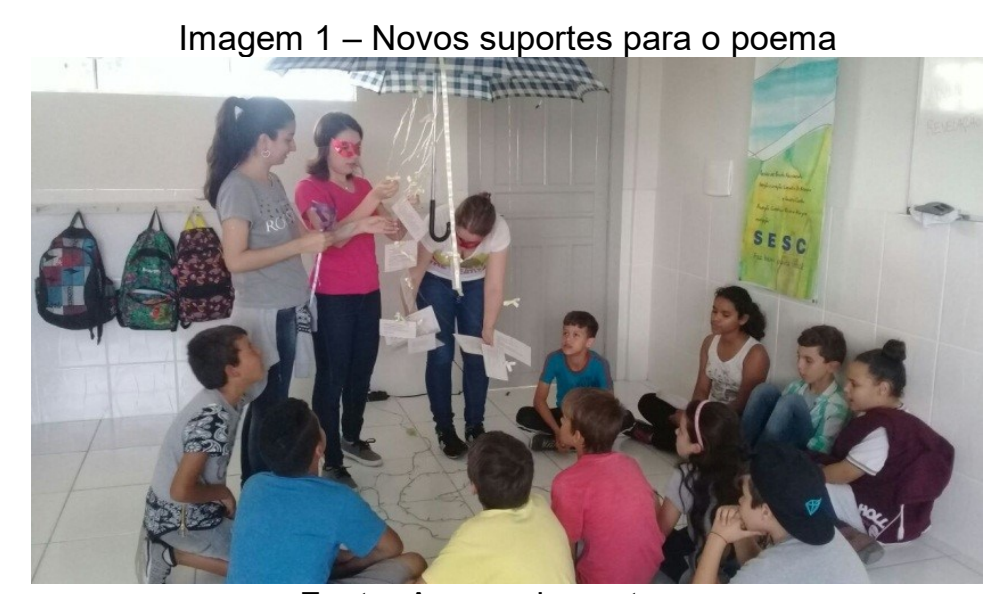

Fonte: Acervo das autoras.

Com o objetivo de proporcionar aos alunos e aos bolsistas um momento de contato estético com haicais e poemas de Manoel de Barros, Adélia Prado, Manuel Bandeira e Ledo Ivo, os bolsistas produziram poemas-objeto antes mesmo de nomeá-los e conceituá-los para os alunos da Educação Básica. A seleção de 


\section{Atos de Pesquisa em Educação - ISSN 1809-0354}

Blumenau, v.14, n.1, p.101-122, jan./abr. 2019

DOI: http://dx.doi.org/10.7867/1809-0354.2019v14n1p101-122

escritores, definida pelos bolsistas com a coordenação de área e o professor supervisor, foi sendo expandida ao longo das mediações, tendo em vista a exploração das intertextualidades possíveis em cada poema lido. O poema-objeto foi introduzido gradativamente, como um suporte material diferente para outros textos literários, durante as intervenções no CEDIN Napoleão de Souza. Segundo Mario Pedrosa, a poesia é sempre fenomenológica, mesmo que elaborada com precisão construtiva, pois as palavras, veículos de significação, sempre retornam "[...] ao mundo dos conceitos, ao mundo do verbo" (PEDROSA, 1977, p. 146). Entendemos, portanto, que poemas-objeto potencializam e são geradores de contaminações estéticas.

O contato com esses objetos deu-se em um clima de surpresa e encantamento, na troca de olhares. Ao se disporem em torno do poema-objeto (Imagem 2), as mãos em contato com um suporte literário diferente transpiravam vida. Para Neitzel, Cruz e Weiss (2017, p. 127), “[...] a leitura do literário, para afetar o leitor, necessita ser sentida, habitar em nós, o que implica ser vivida como experiência".

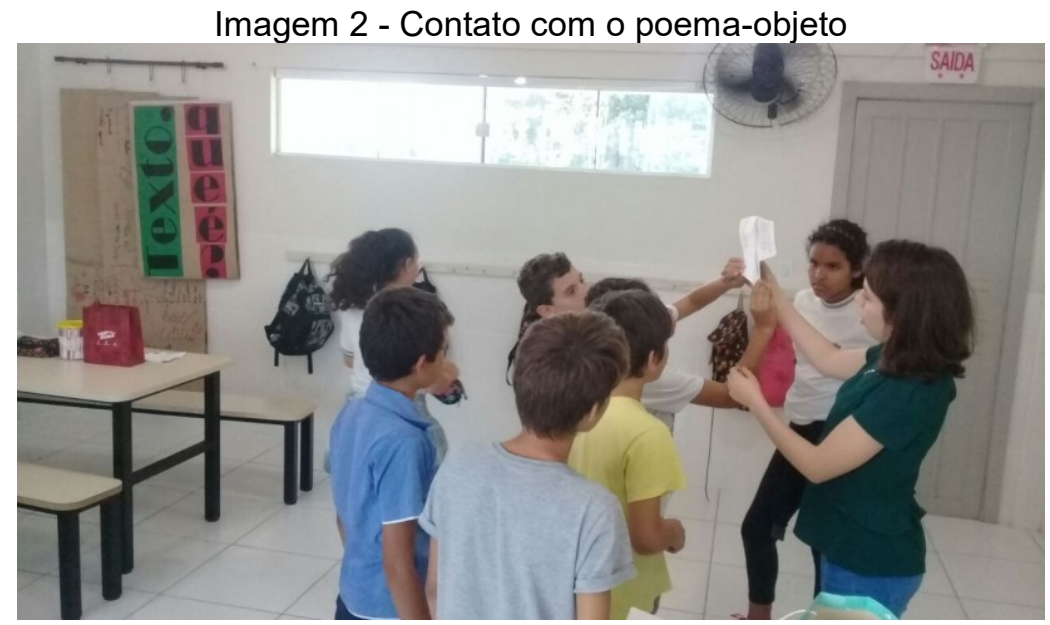

Fonte: Acervo das autoras.

O texto literário foi apresentado em suportes múltiplos, e, em meio a muitos poemas, os bolsistas realizaram uma leitura dramática para o grupo objetivando mostrar possibilidades de exploração do texto literário pela experiência como acontecimento, no sentido proposto por Heidegger (2003). Assim, a escolha do texto 


\section{Atos de Pesquisa em Educação - ISSN 1809-0354 \\ Blumenau, v.14, n.1, p.101-122, jan./abr. 2019 \\ DOI: http://dx.doi.org/10.7867/1809-0354.2019v14n1p101-122}

deu-se pela sua identificação com o grupo de alunos, isto é, os bolsistas juntamente aos alunos escolheram um texto poético que mais os envolveu, que os afetou sinestesicamente.

Segundo Neitzel e Carvalho (2016), a leitura por meio do corpo é capaz de mobilizar o leitor a entrar no universo literário e também de recriar suas interpretações, sem se esquecer de que é pelo corpo que os sentidos são percebidos. A estesia do momento levou-os a compartilhar com seus pares os textos que entre eles mais se identificaram, como o poema $A$ onda, de Manuel Bandeira, por conta de sua sonoridade.

A onda
a onda anda
aonde anda
a onda?
a onda ainda
ainda onda
ainda anda
aonde?
aonde?
a onda a onda
Manuel Bandeira (1996, n.p.).

Diferentes formas e gestos de lê-lo por meio do corpo foram experimentados pelos alunos. A potência da palavra, da poesia, da literatura, foi explorada por meio da apreciação, da fruição, o que possibilitou que os estudantes fossem tocados, isto é, afetados pelo texto, compartilhando com os colegas as sensações percebidas por meio da sua leitura corporal. De acordo com Cé Soares, Neitzel e Carvalho (2016, p. 54), "[...] o poema é objeto cultural de nutrição, que ao ser compartilhado sem pressa, com afetos e trocas [...]", possibilita que o corpo possa coletar sensações e deixar-se alimentar pela estesia, pelo saber sensível.

Esse movimento diante do poema-objeto, do haikai e de outros poemas, alterou a relação dos bolsistas e dos estudantes com a linguagem literária, ampliando sua compreensão sobre a literatura pela leitura fruitiva. Fazer uma experiência pensante com a linguagem implica em renunciar a relação anterior que se tinha com a coisa e exige prontidão para um outro relacionamento. Prontidão que se manifesta pela escuta do outro e pelo consentimento, pelo deixar-se tomar 


\section{Atos de Pesquisa em Educação - ISSN 1809-0354 \\ Blumenau, v.14, n.1, p.101-122, jan./abr. 2019 \\ DOI: http://dx.doi.org/10.7867/1809-0354.2019v14n1p101-122}

(HEIDEGGER, 2003). Dessa forma, os bolsistas trouxeram à sala de aula objetos propositores que os auxiliassem à proposição de uma experiência poética, que fossem mote para encontros literários permeados pela curiosidade, pesquisa, alegria, encontros. Objetos propositores são aqueles que disparam a imaginação e a cognição, que permitem o estabelecimento de relações, de trocas, de interações, como uma música, uma imagem, um livro e até mesmo um objeto do dia a dia.

\section{O ENCONTRO DO TEXTO LITERÁRIO: CONCEITOS, PALAVRAS, OBJETOS...}

Como podemos extrair do poema a experiência que o poeta se dedicou a elaborar junto à palavra senão pela entrega à experiência da leitura propriamente dita? Diante do texto, os bolsistas buscaram provocar nos alunos o desejo pela leitura por meio do diálogo, pois mediar exige momentos de escuta, de trocas. Logo, procuraram estabelecer possibilidades de mediação que levassem os alunos à leitura do texto de Clarice Lispector, Uma galinha (LISPECTOR, 2009), explorando as relações possíveis entre o texto literário e um objeto propositor, um sapato velho. O objeto propositor exerce a função de estabelecer o elo com a palavra. Os bolsistas propuseram a prática da reflexão pelo diálogo entre os sujeitos acerca daquele objeto, o sapato (Imagem 3), que mais tarde seria um poema-objeto, porque a dinâmica visava levá-los a produzir conceitos que o elegessem a essa categoria (Imagem 4). Segundo um dos estudantes: "o sapato velho é de um homem que o usou muito durante sua vida".

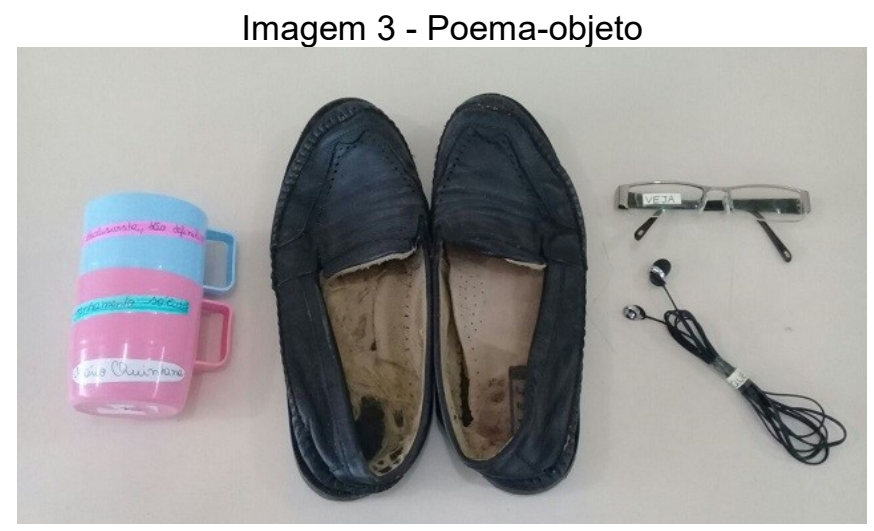

Fonte: Acervo das autoras. 


\section{Atos de Pesquisa em Educação - ISSN 1809-0354 \\ Blumenau, v.14, n.1, p.101-122, jan./abr. 2019 \\ DOI: http://dx.doi.org/10.7867/1809-0354.2019v14n1p101-122}

110

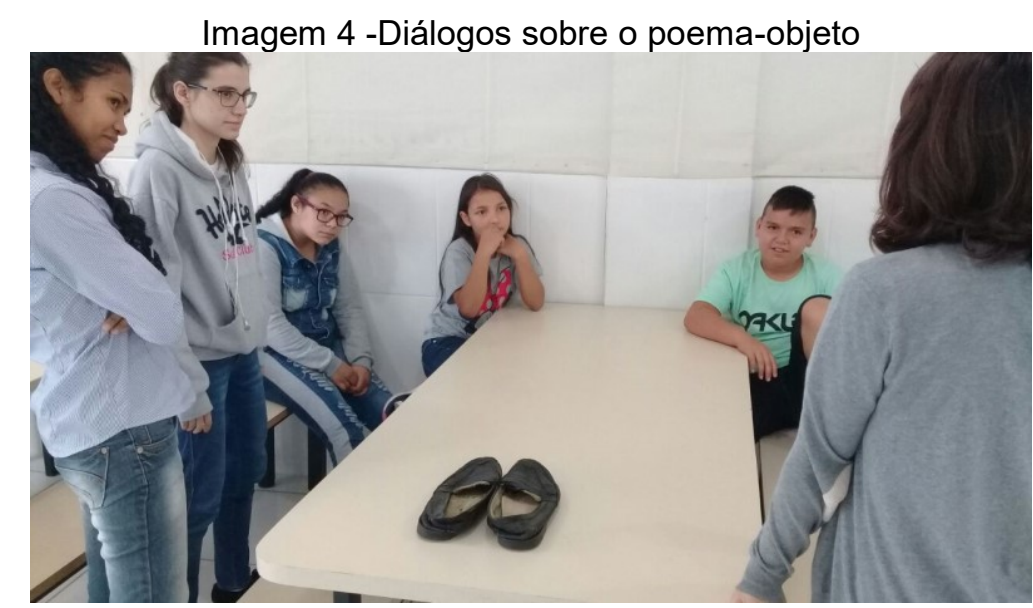

Fonte: Acervo das autoras.

Neitzel e Carvalho (2016) entendem que o processo de formação de leitores depende da relação de intimidade estabelecida entre leitor e obra, pois a cada leitura o leitor emerge em um processo de interpretação e é estimulado a conectar e criar novos mundos. Por isso, os bolsistas foram propondo atividades de leitura diversas que poderiam ser relacionadas ao conto de Clarice Lispector, pois a ideia era de aguçar, por meio de outros textos, a curiosidade em relação ao conto e, por último, à produção de poemas-objeto.

Assim, da observação de poemas-objeto produzidos pelos bolsistas, da leitura de poemas disponíveis em vários suportes, do diálogo a partir de objetos propositores como o sapato velho, chegou-se ao poema Utopia, de Fernando Birri citado por Eduardo Galeano.

A utopia está lá no horizonte.

Me aproximo dois passos, ela se afasta dois passos.

Caminho dez passos e o horizonte corre dez passos.

Por mais que eu caminhe, jamais alcançarei.

Para que serve a utopia?

Serve para isso: para que eu não deixe de caminhar.

Fernando Birri (2015, n.p.).

As conexões tecidas entre o poema de Birri (2015) e o objeto propositor "sapato" despertaram nos alunos as vozes: "caminhada e horizonte". A palavra "Utopia", que nomeia o poema, gerou discussões múltiplas sobre seu significado. Um espaço de sonhos e de desejos foi então criado em sala de aula, provocados pelo conceito inspirado pelo objeto propositor. Os estudantes expressaram seus 


\section{Atos de Pesquisa em Educação - ISSN 1809-0354 \\ Blumenau, v.14, n.1, p.101-122, jan./abr. 2019 \\ DOI: http://dx.doi.org/10.7867/1809-0354.2019v14n1p101-122}

projetos de vida: "ser professora de creche", "viajar para Paris", "ser jogador de tênis de mesa", "ter uma casa com toda a família reunida".

A atividade proporcionou aos estudantes possibilidades de compartilhar suas impressões e dialogar com o outro sobre seus saberes, por isso comentaram que era preciso usar sapatos para não machucar os pés enquanto perseguem seus sonhos. Na procura constante pelos próprios objetivos, os sonhos quando realizados serão substituídos por outros. Está-se, assim, sempre em movimento de busca, realização pessoal, o que implica em perceber os novos horizontes que vão sendo abertos na experiência.

O grupo de estudantes foi convidado a desenvolver inicialmente a leitura do poema no modo silencioso para, posteriormente, tecer relações diversas com seus pares e com a obra lida. Partindo do princípio de que os encantamentos com o texto passa pela relação fruitiva que estabelecemos com ele e que a leitura como acontecimento é algo que precisa penetrar no leitor pelos sentidos, foi proposta uma leitura em voz alta do poema (Imagem 5) de forma coletiva por meio de sussurros, de risadas e de tristezas. A partir dessa atividade perceptiva, o sujeito descobre o texto e amplia suas possibilidades de apreciá-lo, uma leitura que começa pela brincadeira e que pode levar à estesia.

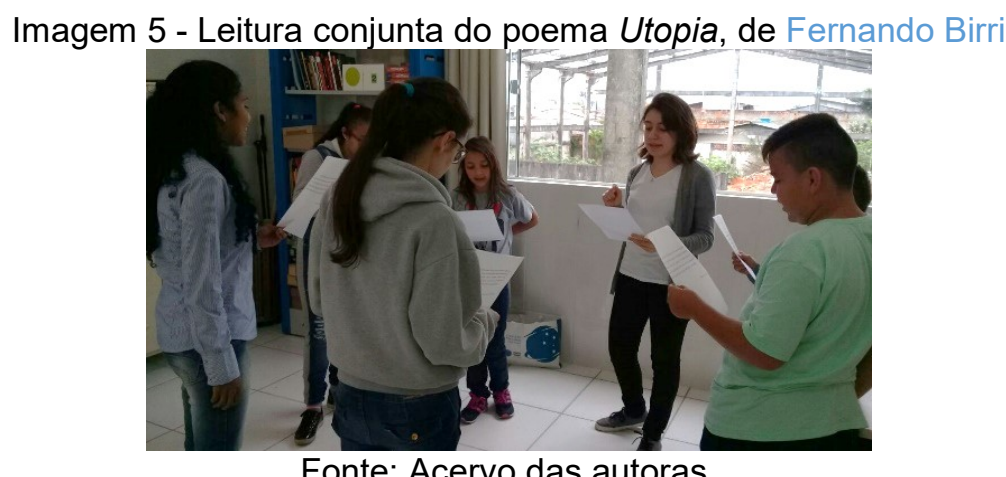

Entendemos que uma mediação literária adequada promove o diálogo, a compreensão de conceitos, as pausas de leitura para dar lugar à escuta do outro, e, nesse processo dialógico, aperfeiçoam-se conceitos pelas trocas, pela partilha. Esse grupo de licenciandos objetivava trazer à tona discussões sobre o poema-objeto, e, por isso, voltou a atenção ao objeto propositor "sapato" que deflagrou uma nova 


\section{Atos de Pesquisa em Educação - ISSN 1809-0354 \\ Blumenau, v.14, n.1, p.101-122, jan./abr. 2019 \\ DOI: http://dx.doi.org/10.7867/1809-0354.2019v14n1p101-122}

roda de conversa (Imagem 6). Que conceito ele carrega consigo? Um dos alunos afirmou: "Faço escolhas ao escolher o sapato que quero usar naquele dia para construir uma história e alcançar minha utopia".

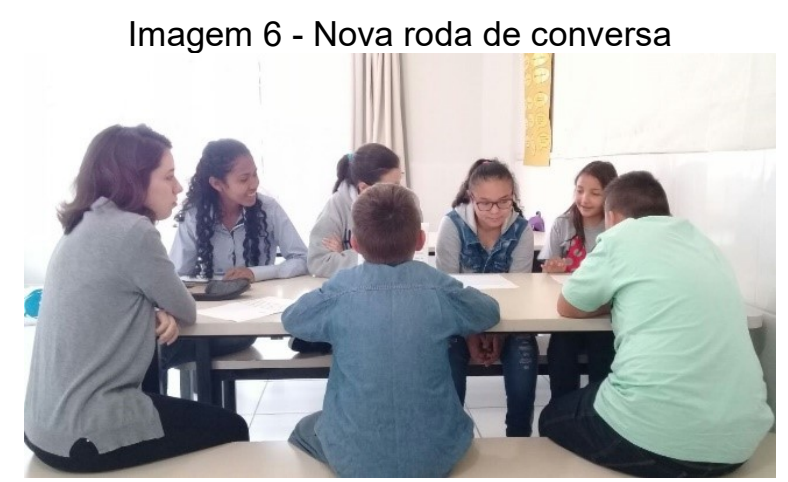

Fonte: Acervo das autoras.

Ao associar a palavra "escolhas" ao sapato, construiu-se um poema-objeto para, nesse processo de produção, chegar-se ao texto literário Uma galinha, de Clarice Lispector: "Quem de vocês já andou em cima do telhado?". Essa pergunta provocou-os a adentrar no texto para efetuar a descoberta. Da conversa à leitura silenciosa e desta à conversa. Da conversa à descoberta: "Ah! Já descobri quem anda em cima do telhado".

Foi por meio desse movimento que se fez a passagem para o conto de Clarice Lispector, apresentado pelos bolsistas na forma de contação de histórias. A vivência propiciada pela contação de história permite que o leitor receba o texto por outros sentidos, além da visão; retome a história e estabeleça uma coexistência do texto oral e do escrito. Como observam Neitzel e Carvalho (2016, p. 148): "Influenciado pela performance do contador, pela audição poética, um desejo de encontro com o texto é liberado e o leitor, na roda de leitura, entrega-se ao livro, em um movimento silencioso de busca e recuperação de outros sentidos".

Muitas vozes foram despertadas pelo texto literário e compartilhadas entre a turma, tais como: "Não mate a galinha!", "Mataram-na, comeram-na e passaram-se anos". O ser humano como sujeito imprevisível e a galinha como ser irracional foram também algumas das abordagens da discussão que partiu do texto literário. Um dos alunos ainda comentou: "Não quero mais comer galinha depois desse conto!". A leitura do literário desperta emoções e abre espaços para o processo de fruição 


\section{Atos de Pesquisa em Educação - ISSN 1809-0354}

Blumenau, v.14, n.1, p.101-122, jan./abr. 2019

DOI: http://dx.doi.org/10.7867/1809-0354.2019v14n1p101-122

estética, ao mesmo tempo que age como potencializadora de aprendizagens conceituais, de saberes outros, de forma integrada, sem apartamentos do sensível e do inteligível.

Ao se abordarem vários textos permeados pelo diálogo simultaneamente, foise desenhando uma leitura autônoma e a elaboração de conceitos, que implica na proficiência linguística que vai sendo melhorada pelos sentidos. A mediação pelo diálogo e pela troca, segundo Rancière (2013), é emancipadora porque permite a construção de conhecimentos, dando voz ao grupo enquanto que a explicadora reproduz valores. Todo esse movimento encaminhou-os à produção de poemas conceituais, os poemas-objeto.

\section{A CONSTRUÇÃO DE POEMAS-OBJETO}

A mediação do texto literário envolve uma abertura do mediador para a escuta da voz do outro, assim como uma atenção para a voz do texto, identificando que relações ele nos alça a construir (Imagem 7). Mediar, nesse sentido, é provocar o leitor a entrar no texto por diferentes vieses e com auxílio de outros textos e linguagens, de forma a produzir interações, pensamentos, conversas. O poemaobjeto é um texto literário provocativo porque está envolto em ambiguidades, é uma obra conceitual que nos convida a dialogar porque ela não explicita; seu sentido é subliminar. A fala dos alunos revela que o poema-objeto é um "poema através de um objeto" e que "carrega um significado".

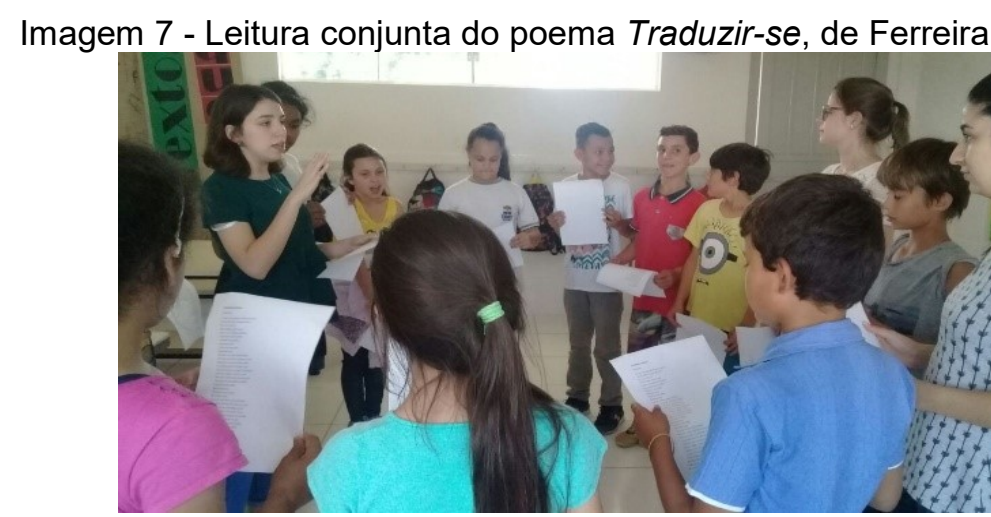

Fonte: Acervo das autoras. 


\section{Atos de Pesquisa em Educação - ISSN 1809-0354}

Blumenau, v.14, n.1, p.101-122, jan./abr. 2019

DOI: http://dx.doi.org/10.7867/1809-0354.2019v14n1p101-122

O literário chama o leitor à reflexão porque é marcado por desvios das normas comunicativas e, quando estabelecemos relações dele com outros textos, nossas possibilidades interpretativas se ampliam. Diante do poema-objeto (Imagem 8), um aluno declara: "Não podemos ser iguais, temos que ser nós mesmos".

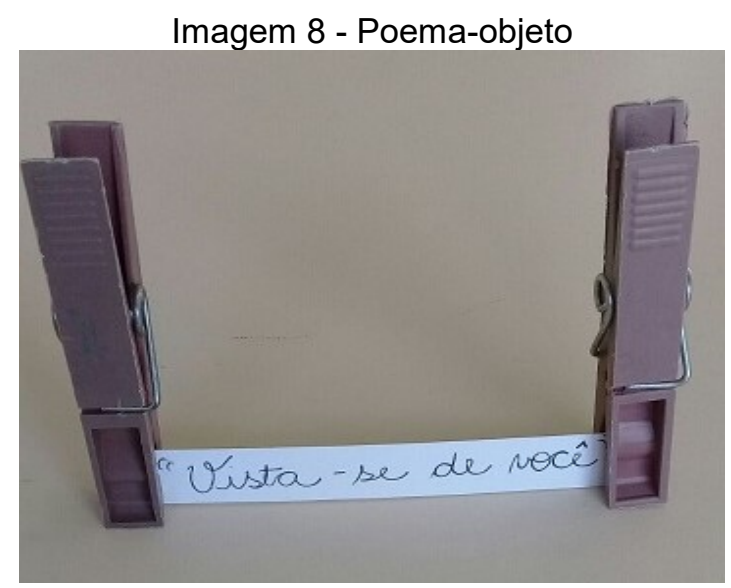

Fonte: Acervo das autoras.

Para Neitzel, Cruz e Weiss (2017, p. 123), a forma como passamos a perceber e ressignificar o mundo "[...] depende da relação que estabelecemos com a obra, que é também dependente de como ela nos chega, de nossas motivações para lê-la". As impressões de leitura elaboradas diante do poema-objeto foram consequências também do diálogo que se possibilitou anteriormente no encontro com o poema de Ferreira Gullar.

\section{Traduzir-se:}

Uma parte de mim é todo mundo; outra parte é ninguém: fundo sem fundo. Uma parte de mim é multidão:

outra parte estranheza e solidão. [...] Uma parte de mim é só vertigem; outra parte, linguagem. 


\section{Atos de Pesquisa em Educação - ISSN 1809-0354 \\ Blumenau, v.14, n.1, p.101-122, jan./abr. 2019 \\ DOI: http://dx.doi.org/10.7867/1809-0354.2019v14n1p101-122}

de vida ou morte -

será arte?

Ferreira Gullar (2016, n.p.).

Experiência que comprova que as aprendizagens não ocorrem somente pelo cognitivo, mas também pelos sentidos e pelas emoções, reafirmando o que diz Duarte Jr. (2010) ao propagar que o mundo nos chega pelos sentidos e que o apartamento do sensível e do inteligível representa uma visão racional e restrita das coisas. Esta não pode ter lugar quando falamos de educação, pois tudo o que fazemos e somos é fruto de nossas vivências, as quais não são apenas racionais ou sensíveis, dão-se entrelaçadas.

Uriarte, Neitzel e Carvalho (2016) discutem como a arte permite uma percepção ampliada de nossa própria realidade e de como ela nos possibilita uma educação estética, uma experiência que não aparta o sensível do inteligível, mas que nos afeta, atravessa-nos, permitindo-nos perceber a literatura como um acontecimento e, portanto, como experiência no sentido abordado por Larrosa (2016) e por Heidegger (2003). É essa compreensão que respalda as ações dos pibidianos ao proporem o texto literário, entendendo que ele é um poderoso instrumento para a educação estética quando mediado adequadamente. Por meio das artes, novos encontros ensejam (re)significações de mundos.

Essa experiência sensível com o poema-objeto, esse artefato aberto, prenhe de significações, foi dirigida para a construção em grupos de poemas-objeto. Exercício coletivo que envolveu orientadores (bolsistas) e orientandos (grupos de estudantes) para que internalizassem o processo, tornando-se sujeitos que leem, mas que também produzem, provocando o outro, mas também se provocando. Após esse exercício, cada bolsista expôs cinco objetos e cinco trechos de poemas para mediar a compreensão sobre o poema-objeto e a produção em pequenos grupos (Imagem 9). O diálogo compartilhado e a leitura de outros textos relacionais são mediações prévias necessárias para a entrada em qualquer texto literário. Todo esse movimento pautado pela troca visou também a possibilitar uma experiência sensível que se dá por meio de encontros com a arte e com experiências perceptivas do olhar, do escutar e do tocar, como sinaliza Martins (2012); atividades que contribuem para a formação estética quando são planejadas de 


\section{Atos de Pesquisa em Educação - ISSN 1809-0354 \\ Blumenau, v.14, n.1, p.101-122, jan./abr. 2019 \\ DOI: http://dx.doi.org/10.7867/1809-0354.2019v14n1p101-122}

forma que permitem ao outro se manifestar, pensar, trocar ideias, escutar o outro, ampliar seus olhares. Entendemos que a literatura tem uma potência estésica quando trabalhada como arte, quando suas funções estéticas são respeitadas ${ }^{2}$.

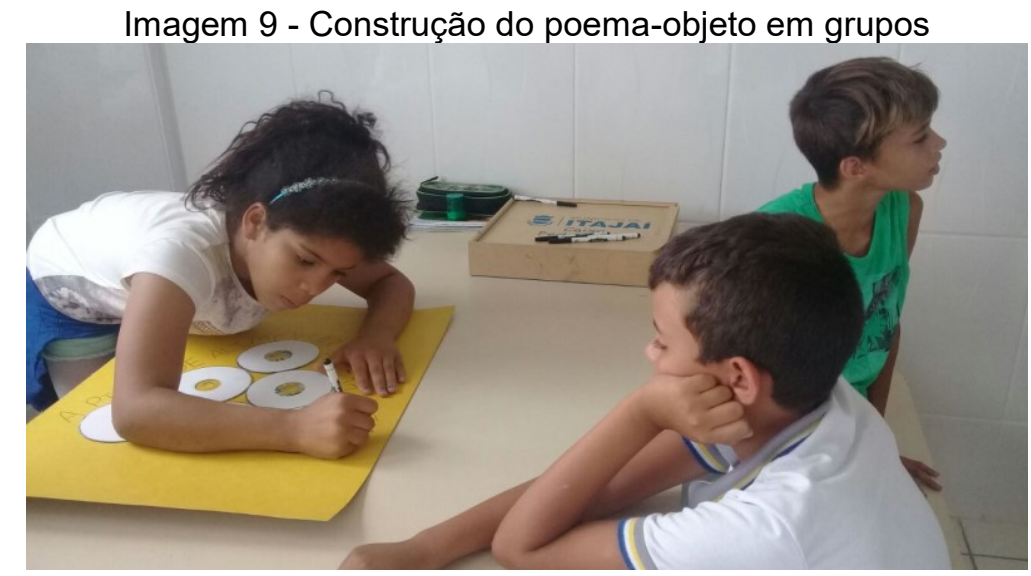

Fonte: Acervo das autoras.

Entretanto, como afetar o outro pelo texto literário? Neitzel, Cruz e Weiss (2017, p. 127) afirmam que: "Fazer da leitura do literário uma experiência é não apenas entrar no texto, tergiversá-lo de várias formas para compreendê-lo, mas é, sobretudo, deixar-se afetar por ele e deixá-lo entrar na nossa própria existência". Esse afetamento não está relacionado somente à forma de mediação proposta, mas também ao mundo de referência dos leitores. Dos poemas lidos por um dos grupos, o que mais os afetou foi Vou-me embora pra Pasárgada, de Manuel Bandeira.

Vou-me embora pra Pasárgada Lá sou amigo do rei

Lá tenho a mulher que eu quero $\mathrm{Na}$ cama que escolherei Vou-me embora pra Pasárgada [...].

Manuel Bandeira (1986, p. 90).

A partir desse poema e de uma folha sulfite, os alunos escolheram o design do futuro poema-objeto, um aviãozinho. Partiu-se, portanto, de uma ideia que surgiu

\footnotetext{
2 Compreendemos, como Duarte Jr. (2010), que a função estética da literatura promove a estesia e vice-versa, tendo em vista a origem grega da palavra aisthesis como estesia. Explorar a potência estésica da literatura é explorar sua potência estética.
} 


\section{Atos de Pesquisa em Educação - ISSN 1809-0354}

Blumenau, v.14, n.1, p.101-122, jan./abr. 2019

DOI: http://dx.doi.org/10.7867/1809-0354.2019v14n1p101-122

da leitura do texto literário para a produção do poema-objeto. Movimento inverso ao que foi produzido quando se trabalhou com o conto de Clarice Lispector.

$\mathrm{Na}$ construção do objeto literário, percebeu-se um movimento colaborativo entre os integrantes do grupo (Imagem 10). Um estudante fez a dobradura no papel branco, transformando-o em aviãozinho; outro escreveu com muito cuidado o conceito que seria representado pelo objeto; outro verbalizou muitas ideias criativas em sua decoração; e outro liderou as discussões sobre o significado desse poemaobjeto. O processo de construção do poema-objeto mobilizou vários conhecimentos e exigiu do grupo integração, respeito à opinião do outro, planejamento e pesquisa, "[...] um exercício intelectual e afetivo que leva à reflexão, à autonomia, ao querer e ao gostar, que pode alargar nossas potencialidades intelectuais e, também, a percepção de nós mesmos e do outro" (NEITZEL; CRUZ; WEISS, 2017, p. 128).

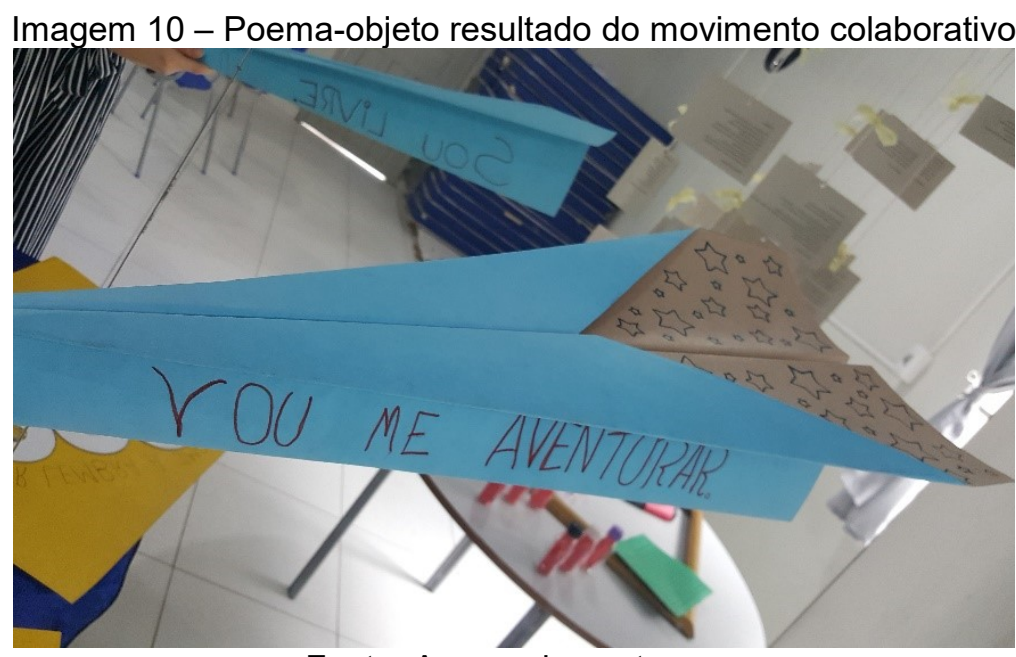

Fonte: Acervo das autoras.

O poema de Manuel Bandeira (1986) despertou nos alunos, mediados por uma das bolsistas, a sensação e o desejo de "descobrir novos horizontes" e, além disso, "procurar um desafio para si mesmo". O conceito do poema-objeto estava então encarnado. Em uma das asas do avião, eles escreveram em caixa alta "SOU LIVRE" e na outra "VOU ME AVENTURAR". Seus depoimentos levam-nos a perceber que a mediação proposta conseguiu atingir o objetivo de estabelecer uma "[...] relação com os livros de amor e de paixão, construída na própria leitura, na 


\section{Atos de Pesquisa em Educação - ISSN 1809-0354 \\ Blumenau, v.14, n.1, p.101-122, jan./abr. 2019 \\ DOI: http://dx.doi.org/10.7867/1809-0354.2019v14n1p101-122}

descoberta, no (re)significar, no encontro e no desencontro" (NEITZEL; CRUZ; WEISS, 2017, p. 128).

Os estudantes apresentaram seu poema-objeto para a turma explicando o conceito que ele carregava consigo. Protagonistas de sua própria aprendizagem tornaram-se mais autônomos e abertos a novas experiências estésicas. Todo esse movimento permitiu ao grupo a internalização da concepção de que a literatura não é só arte da palavra, mas também manifestação artística que faz uso de outras linguagens, como a visual. A proposta foi trazer a literatura para a sala de aula como experiência estética, no sentido atribuído por Larrosa (2016) e Heidegger (2003). Uma experiência de leitura que é desejada como foi por Rosálio, personagem de $O$ Voo da Guará Vermelha, de Maria Valéria Rezende:

O Bugre estava doente, doença que não se cura, cada dia mais cansado, quando eu pedia uma história, Às vezes adormecia sem acabar de contar, eu ficava agoniado querendo saber o fim, remexia aqueles livros, virava de um lado e de outro, olhava por muito tempo algum desenho que tinham, sabendo que nesta vida a coisa que eu mais queria era aprender a ler livros, que quando o Bugre morresse e eu fosse um pouco maior ia sair pelo mundo por mor de aprender a ler, porque ali na nossa Grota ninguém podia ensinar. (REZENDE, 2014, p. 49).

Por meio da leitura, destinos são mudados e, com Rosálio, aprendemos que sua relação com a escrita, com o texto literário, deu-se pela mediação do Bugre. Foi por ela que ele despertou seu desejo e abriu caminhos para novas experiências, alimentou seu sonho incansável de aprender a ler, o que o levou a ganhar o mundo "por mor" de encontrar alguém que o ensinasse a ler para poder desvelar aquela vida que pulsava nos livros, naquele tesouro que se encontrava em uma caixa, herança do Bugre. Isso nos leva a afirmar que o texto ensina, e muito, mas pelo viés artístico, na e pela relação que construímos com ele. Ao ser afetado pela literatura oral, Rosálio adquiriu novas lentes para enxergar e atuar no mundo. Com essa personagem, assim como com nossos sujeitos de pesquisa, reafirmamos que razão e sensibilidade não podem ser apartados no processo da leitura do literário, pois ela nos exige ser e estar no texto, habitá-lo.

Ao observar todo esse percurso dos pibidianos, entendemos, como Heidegger (2003, p. 131), que: "Experiência é percorrer um caminho", e a experiência do literário ocorre quando atentamos para nossa relação com a linguagem, na 


\section{Atos de Pesquisa em Educação - ISSN 1809-0354 \\ Blumenau, v.14, n.1, p.101-122, jan./abr. 2019 \\ DOI: http://dx.doi.org/10.7867/1809-0354.2019v14n1p101-122}

experiência que fazemos com ela, na harmonia que produzimos no processo, o que nos exige "[...] deixarmo-nos tocar propriamente pela reinvindicação da linguagem" (HEIDEGGER, 2003, p. 121). Fazer uma experiência pensante com a linguagem "[...] significa que esse algo nos atropela, nos vem ao encontro, chega até nós, nos avassala e transforma" (HEIDEGGER, 2003, p. 121).

\section{CONSIDERAÇÕES}

Esta pesquisa teve como objetivo discutir as possibilidades de mediação literária do poema-objeto exploradas pelos bolsistas do PIBID no CEDIN Napoleão de Souza, Itajaí, SC. Identificamos que os bolsistas partiram da hipótese de que, por meio do poema-objeto, os alunos poderiam internalizar, com mais facilidade, a concepção de literatura como arte e que o poema-objeto poderia ser também um objeto propositor que aguçasse a percepção dos leitores para textos literários verbais. Dessa forma, os bolsistas propuseram dois movimentos: do poema-objeto para o texto literário verbal e, deste, para o poema-objeto.

Os resultados sinalizam que a postura dos bolsistas como "mestres emancipadores", em sala de aula, abriu espaço para os estudantes serem protagonistas de sua própria aprendizagem; as propostas literárias possibilitaram diálogos sobre o universo poético e estabeleceram relações com outras linguagens artísticas do cotidiano. Um espaço de sonhos, de provocações, propícias à formação de leitores na escola, foi então criado, principalmente por meio dos significados e dos conceitos suscitados ao longo do encontro com outros textos, assim como pelo poema-objeto construído. Como uma nova experiência literária, ao se transportar para outros suportes, o poema-objeto inseriu-os em um movimento diferente de percepção da literatura, o que provocou reflexões e interações sobre uma nova perspectiva da arte literária e percepções de uma das marcas da cultura contemporânea, "o mosaico" que permite olhares multifacetados, expressos pelas imbricações de linguagens.

As mediações literárias propostas evidenciaram uma concepção de mediação não diretiva, não explicadora, mas emancipadora, que considera o outro, o seu 


\section{Atos de Pesquisa em Educação - ISSN 1809-0354 \\ Blumenau, v.14, n.1, p.101-122, jan./abr. 2019 \\ DOI: http://dx.doi.org/10.7867/1809-0354.2019v14n1p101-122}

desejo, os seus saberes e gostos, as suas preferências. Nesse sentido, mediar exige do mediador o silêncio, a suspensão de sua narrativa para que a escuta tenha lugar e para que um discurso não seja imposto, mas proposto, motivo para o diálogo.

A leitura do literário como experiência dá-se assim no fazer (e este não está apartado do pensar), na própria leitura e no diálogo que ela provoca, nas relações que estabelecemos diante do texto. Para isso, são necessários a prontidão e o consentimento do leitor. Assim sendo, a experiência com a linguagem é diferente da experiência sobre a linguagem, pois é na primeira que nos libertamos do hábito de ouvir apenas aquilo que já sabemos, renunciando nossas certezas para re-anunciar nossa abertura para a aprendizagem e para um novo e outro relacionamento com o texto literário.

\section{ADAIR DE AGUIAR NEITZEL}

Pós-Doutora pela Universidade Paris VII. Doutora em Literatura pela Universidade Federal de Santa Catarina (UFSC). Professora do corpo docente permanente do Programa de Mestrado e Doutorado em Educação e do curso de Letras da Universidade do Vale do Itajaí (UNIVALI).

\section{TAIZA MARA RAUEN MORAES}

Doutora em Literatura pela Universidade Federal de Santa Catarina (UFSC). Coordenadora do Proler-Univille. Professora do Mestrado em Patrimônio Cultural e do curso de Letras da Universidade de Joinville (UNIVILLE).

\section{AMANDA DEMÉTRIO DOS SANTOS}

Acadêmica do Curso de Letras da Universidade do Vale do Itajaí (UNIVALI).

\section{REFERÊNCIAS}

BANDEIRA, M. Vou-me embora pra Pasárgada. In: BANDEIRA, M. Bandeira a vida inteira. Rio de Janeiro: Alumbramento, 1986. 


\section{Atos de Pesquisa em Educação - ISSN 1809-0354 \\ Blumenau, v.14, n.1, p.101-122, jan./abr. 2019 \\ DOI: http://dx.doi.org/10.7867/1809-0354.2019v14n1p101-122}

BANDEIRA, M. A onda. Alô Escola, ponto.com - Poesia. 1996. Disponível em: <http://cmais.com.br/aloescola/literatura/poesias/manuelbandeira_aonda.htm>. Acesso em: 7 dez. 2017.

BARTHES, R. O prazer do texto. São Paulo: Perspectiva, 2003.

BELL, L. O código das águas. São Paulo: Global, 2001.

BIRRI, F. Utopia. In: GALEANO, E. Para que serve a Utopia?. CONTI outra, 17 jan. 2015. Disponível em: <http://www.contioutra.com/para-que-serve-utopia-eduardogaleano/>. Acesso em: 7 dez. 2017.

CÉ SOARES, A. F.; NEITZEL, A. de A.; CARVALHO, C. A potência cultural da escola: estudos sobre mediação e formação estética. In: NEITZEL, A. de A.; CARVALHO, C. (Orgs.). Mediação cultural, formação de leitores e educação estética.Curitiba: CRV, 2016. p. 53-66.

DUARTE JR., J. F. O sentido dos sentidos: a educação (do) sensível. 5. ed. Curitiba: Criar edições, 2010.

GULLAR, F. Traduzir-se. 2016. Disponível em:

<http://www.ufrgs.br/rotascriticas/textos/Traduzir-se\%20Ferreira\%20Gullar.pdf>. Acesso em: 7 dez. 2017.

HEIDEGGER, M. A caminho da linguagem. Tradução Marcia Sá Cavalcante Schuback. Petrópolis: Vozes; Bragança Paulista: Editora Universitária São Francisco, 2003.

LARROSA, J. Tremores: escritos sobre experiência. Tradução Cristina Antunes e João Wanderley Geraldi. Belo Horizonte: Autêntica, 2016.

LISPECTOR, C. Uma galinha. In: LISPECTOR, C. Laços de família. Rio de Janeiro: Rocco, 2009. p. 30.

MARTINS, M. C. Expedições instigantes. In: MARTINS, M. C.; PICOSQUE, G. (Orgs.). Mediação cultural para professores andarilhos na cultura. 2. ed. São Paulo: Intermeios, 2012. p. 9-22.

MERLEAU-PONTY, M. Fenomenologia da percepção. Tradução Carlos Alberto Siqueira de Moura. 2. ed. São Paulo: Martins Fontes, 1999. 


\section{Atos de Pesquisa em Educação - ISSN 1809-0354}

Blumenau, v.14, n.1, p.101-122, jan./abr. 2019

DOI: http://dx.doi.org/10.7867/1809-0354.2019v14n1p101-122

NEITZEL, A. de A.; CARVALHO, C. A movência do leitor na leitura do literário. In: NEITZEL, A. de A.; CARVALHO, C. (Orgs.). Mediação cultural, formação de leitores e educação estética. Curitiba: CRV, 2016. p. 143-157.

NEITZEL, A. de A.; CRUZ, D. V. da N.; WEISS, C. S. A leitura do literário como acontecimento. In: NEITZEL, A. de A. et. al. (Orgs.). Cultura, escola e educação criadora: diálogos sobre experiências estéticas na educação. Itajaí: UNIVALI; Florianópolis: Dois Por Quatro, 2017. p. 123-136.

PEDROSA, M. Poeta \& pintor modernista. In: AMARAL, A. (Org.). Projeto Construtivo Brasileiro na arte: 1950-1962. Rio de Janeiro: Museu de Arte Moderna; São Paulo: Pinacoteca do Estado de São Paulo, 1977. p. 145-155.

RANCIÈRE, J. O mestre ignorante: cinco lições sobre a emancipação intelectual. Tradução Lilian do Vale. 3. ed. Belo Horizonte: Autêntica, 2013.

REZENDE, M. V. O voo da Guará vermelha. Rio de Janeiro: Objetiva, 2014.

URIARTE, S. Z.; NEITZEL, A. de A.; CARVALHO, C. Formação estética em educação: produções acadêmicas no Brasil. In: NEITZEL, A. de A.; CARVALHO, C. (Orgs.). Mediação cultural, formação de leitores e educação estética. Curitiba: CRV, 2016. p. 187-208. 